\title{
A colaboração dos usuários na divulgação de destinos turísticos baseada no compartilhamento de dados geoprocessados
}

\section{The users cooperation in the marketing of touristic destinations based on data geoprocessing sharing}

\author{
Eduardo Michelotti Bettoni (BETTONI, E. M.) ${ }^{*}$
}

\begin{abstract}
RESUMO - O emprego da tecnologia em turismo tem se intensificado de maneira tão expressiva que os aparelhos de GPS (Global Positioning System) podem ser usados para troca de informações sobre rotas e atrativos. O objetivo desse trabalho foi identificar como esse intercâmbio de informações turísticas vem ocorrendo e, de que forma esses dados podem ser reorganizados e utilizados pelos órgãos públicos de turismo. $\mathrm{Na}$ pesquisa, de caráter exploratório, trabalhou-se com técnicas de coleta por observação e documental/bibliográfica, compreendendo a possível transformação dos dados do GPS, em informação para a divulgação turística.
\end{abstract}

Palavras-chave: Turismo de aventura; Orientação; Geoprocessamento; GPS; Tecnologia em turismo.

ABSTRACT - The use of technology in tourism is such that the GPS devices can be used to exchange information about routes and attractions. The objective of this research was identifying how this exchange of tourist information is made, and how this data can be rearranged and used by public tourism agencies. Based on exploratory strategy, observation and document data collection methods were used in this research, including the possible conversion of GPS data, in information to use in advertising campaigns of public destinations.

Keywords: Adventure tourism; Navigation; Geoprocessing; GPS; Technology in tourism.

\footnotetext{
* Bacharel em Turismo pela Universidade Federal do Paraná (UFPR). Mestrando em Ciência, Gestão e Tecnologia da Informação pelo PPCGI (Programa de Pós-Graduação em Ciência, Gestão e Tecnologia da Informação) - UFPR. Endereço: Rua General Polli Coelho, 683 (Tarumã). CEP: 82800-180 - Curitiba PR (Brasil). Telefone: (41) 9927-3497.E-mail: webtur@ufpr.br
} 


\section{INTRODUÇÃO}

A partir da década de 90, um grupo de "novos turistas" passa a ser considerado nos estudos da área turística, em que características como as viagens em grupo e destinos de sol e praia, foram vistas como ultrapassadas, dando espaço a um novo conceito de demanda. Esse grupo buscava uma nova forma de realização, com alto grau de escapismo, customização (inclusive viagens individuais) e necessidade de "sumir do mapa", buscando destinos inóspitos (de natureza) e com alto grau de isolamento. Aponta-se ainda um desejo por estar no comando durante todo o tempo, assumindo, portanto, alguns riscos (SWARBROOKE et al., 2003).

Considerando somente o turismo de aventura, notam-se algumas especificidades nos desejos de viagens de seus participantes: “[...] resultados incertos, exploração e descoberta, expectativa de recompensas, desafio, perigo e risco [...]" (SWARBROOKE et al., 2003, p. 9). Em complemento ao exposto, o Ministério do Turismo - MTUR (2008) acrescenta a presença de riscos controlados que exigem equipamentos e técnicas necessárias para as práticas.

Entende-se que essa busca do turista em ser independente, aliada a uma nova forma de elaboração e gestão das viagens - muitas vezes autônomas - pode culminar em novas necessidades e, inclusive, de maior preparação, através da busca e análise de informações disponíveis (por exemplo, na Internet) para proceder à definição de um roteiro (MARÍN, 2004).

Uma das características principais desses novos roteiros é o ambiente onde eles ocorrem. Geralmente em atrativos distantes de grandes centros e, em muitos casos, com alguma dificuldade de acesso. Ignarra (2003, p. 14) defende que "[...] o turismo é todo o plano de deslocamento de ida e volta, qualquer seja a motivação, à distância percorrida e a duração de tempo." Relacionando o fator de dificuldade de acesso com a definição anterior, entende-se que há certa complicação quanto à própria divulgação e visitação de determinados atrativos em um mercado em expansão. Através desse problema, identificam-se novas formas de orientação por parte dos turistas nesses ambientes (e 
mesmo na área urbana), sendo uma delas a utilização de aparelhos de GPS $^{1}$ para facilitar deslocamentos, conforme mencionado acima.

O jornalista Belson (2008) aponta uma aproximação dos usuários da Internet com a criação de mapas e roteiros através de recursos tecnológicos. A reportagem relata que nos Estados Unidos, no final de 2007, o item eletrônico de venda mais imediata foi o GPS. Expõe também que os fabricantes do aparelho se caracterizavam pela busca de soluções integradas em portais de mapas de cidades ou mesmo de serviços, com o objetivo final de que esse aparelho se tornasse um bem tão indispensável quanto o celular. A associação foi feita exaltando que com o GPS, o usuário não se perderia em qualquer deslocamento, principalmente urbano.

Smith e Curran (2005) defendem a idéia de expansão de um sistema (guias turísticos) baseado na localização por aparelhos móveis, com a inclusão da funcionalidade do GPS. Os autores salientam que através do uso desse tipo de aparelho, podem ser gerados sistemas de informação e de assistência aos turistas conjugando a precisão da localização (GPS), a disponibilidade de mapas para que as pessoas possam se situar no ambiente (interface) e, por fim, a listagem de serviços e outros componentes da oferta turística, acessados desde o próprio aparelho.

A ABI Research (2007) apontou uma previsão para 2012, de que os usuários de aparelho celular com GPS irão duplicar em relação a 2008. Isso devido à melhoria da qualidade de recepção do sinal e a popularização dos aparelhos, o que proporciona uma perspectiva de barateamento de custos de produção, além do próprio interesse demonstrado pelo usuário.

Considerando esses fatores, torna-se relevante perceber de que maneira as informações obtidas através da captação de dados no uso dos GPS, passam a ser redistribuídas entre os usuários. Uma das principais formas é o compartilhamento através de comunidades na Internet, como é o caso do site TravelbyGPS (2008) que, pela contribuição de usuários experientes, disponibiliza informações sobre diversos atrativos no formato de dados para uso em outro GPS. O site Geobusca (2008), de produção brasileira, possui mais de 26 mil usuários, e tem como missão “[...] fornecer

\footnotetext{
${ }^{1}$ GPS: Global Positioning System, ou Sistema de Posicionamento Global, é composto por 24 satélites que fornecem informações de distância para os aparelhos receptores, chamados de GPS. Em um cálculo matemático a partir da informação de no mínimo três satélites, o usuário do aparelho pode obter um posicionamento de coordenadas exato, proporcionando, portanto uma ferramenta de localização e navegação. (FEATHERSTONE, 2004).
} 
um serviço [...] gratuito e prático, para viajantes, aventureiros [...] que desejam compartilhar locais onde estiveram e caminhos que os levaram até lá".

Analisando a potencialidade dessas informações obtidas e disponibilizadas de maneira espontânea por usuários experientes ou amadores de aparelhos de GPS, nota-se que elas poderiam também ser destinadas à divulgação e desenvolvimento turístico de determinadas regiões, uma vez que, conforme citação anterior a respeito das empresas fabricantes de celular e GPS há uma tendência de disponibilizar anúncios e informações sobre serviços e esse é o motivo pelo qual o recurso está sendo gradativamente adicionado aos aparelhos celulares. O incremento da visitação de atrativos naturais em locais inóspitos pode ser visto como complexo e demandante de muitos recursos humanos e financeiros, uma vez que um bom plano de sinalização tem que ser elaborado para que os turistas tenham acesso aos locais.

A presente pesquisa teve como problema a ser investigado, identificar de que forma os dados compartilhados entre os usuários de GPS (uso pessoal) poderiam ser utilizados pelas instâncias públicas representantes do turismo, como um modo de divulgação de atrativos, principalmente daqueles situados em zonas rurais.

O objetivo deste estudo foi o de descobrir como a disponibilização espontânea de dados fornecidos por usuários de GPS na Internet, gratuitamente, poderia servir como uma maneira das instâncias dos poderes públicos aprimorarem suas bases de dados quanto à divulgação de atrativos. Para tanto, coube: identificar os ambientes virtuais onde as informações coletadas através de aparelhos de GPS são compartilhadas entre usuários; distinguir os principais formatos de arquivos de intercâmbio e comparar as propriedades desses arquivos com as informações necessárias para a promoção turística.

\section{REVISÃO TEÓRICA}

Neste tópico consta a revisão teórica utilizada como base do conhecimento para a discussão e aplicação da pesquisa, sendo dividido em quatro subtópicos. O 2.1 está relacionado à conceituação das atividades de turismo nos ambientes naturais, do ponto de vista principalmente do Ministério do Turismo. A partir das discussões baseadas no 
órgão, segue o subtópico 2.2 sobre as políticas públicas e a maneira como estão inseridas na atividade turística. Neste caso, a ênfase se deu na atuação do governo frente ao marketing turístico de destinos. Em seguida são apontados os aspectos referentes às aplicações da tecnologia em turismo (2.3) e, por fim, de que forma específica o geoprocessamento pode contribuir para o desenvolvimento da atividade (2.4).

\subsection{TURISMO EM AMBIENTES NATURAIS}

As atividades turísticas em ambientes naturais já foram objeto de discussão de vários autores, traduzindo certo grau de dificuldade em adotar conceitos comuns. Vários termos já foram utilizados para designar visitação, nesses ambientes, sendo a atividade primeiramente designada como ecoturismo. Neil e Wearing (2001, p. xvii) já no início de sua obra a esse respeito especificam que este termo (ecoturismo) tem um nome muito simples, e um universo tão complexo por outro lado. Os autores ressaltam o conceito de viagem ecológica como a próxima mania no mundo do turismo: “[...] para alguns, é um subconjunto de atividades turísticas 'baseadas em natureza', para outros, é um nicho de mercado, um tipo específico de turismo de 'interesse especial' [...]”.

O termo ecoturismo abrange vários fundamentos, sendo os principais: uma particular orientação filosófica, a caracterização por motivações específicas, uma abordagem local envolvendo política de desenvolvimento e uma forma de turismo alternativo. Este último é de grande relevância, uma vez que serve como precursor dos conceitos e da origem do ecoturismo. Uma característica voltada ao meio ambiente aponta para a idéia de turismo que minimiza os impactos sobre a natureza, sendo ecologicamente sadio e indo contra práticas descritas em grandes projetos turísticos empreendidos em áreas não anteriormente preparadas. (HOLDEN, 1984 apud NEIL; WEARING, 2001).

É importante diferenciar o Ecoturismo do Turismo de Aventura. Enquanto o primeiro está relacionado a um conceito geral, que define um "sujeito ecológico" (FURLAN, 2003), o segundo está diretamente identificado à idéia da prática de esportes em ambientes naturais, ou ainda artificiais em alguns casos. Uma das premissas mais citadas na bibliografia sobre esse segmento é a questão da relação risco e perigo. Ao

\footnotetext{
${ }^{2}$ HOLDEN, P. Alternative tourism: report on the workshop on alternative tourism with a focus in Asia. Ecumenical Coalition on Third World Tourism, Bangkok, 1984.
} 
introduzir o assunto, Abreu e Timo (In: UVINHA, 2005, p. 51) indicam que "o turismo de aventura é complexo e envolve diversas atividades, com níveis de risco e incidência de perigos bastante diferentes".

Uma publicação específica do MTUR (2008) sobre o assunto reporta ainda a "diversidade" de segmentos e produtos, o que promove a amplitude de possibilidades na oferta. Por outro lado, também implica no alto grau de complexidade em termos de planejamento e gestão da atividade. Outro aspecto é a participação e a interação. A mesma publicação indica uma intensa participação do turista (com o ambiente, outros turistas e guias), sendo ele o protagonista de uma vivência, tornando-o a essência do segmento. Indica também um possível perfil mais encontrado nesse viajante, tendo como características: contribuição para o planejamento da sua própria viagem e exigência de qualidade, segurança, acessibilidade e informação.

Analisando as atividades turísticas dentro de determinadas unidades de conservação, Cruz (2002) entende que as principais modificações geradas no ambiente, durante a implementação do turismo, são relacionadas à criação ou oficialização de caminhos (trilhas) e a sinalização (orientação) dos visitantes. São dois fatores que podem ser entendidos como mitigadores das características de risco e perigo, indicadas por Swarbrooke et al. (2003), como intrínsecas do Turismo de Aventura.

Por outro lado, alguns aspectos essenciais apontados pelo mesmo autor, denotam uma fuga, por determinado tipo de turistas, vistos como "novos turistas", desse modelo de modificações para implementação.

Eles são vistos como mais "experientes" e "independentes", buscando sempre "estar no comando" em seu tempo livre, assumindo determinados riscos por isso, e buscando executar atividades flexíveis através de uma nova atitude no processo de compra (SWARBROOKE et al., 2003).

Um exemplo, comentando pela Confederação Brasileira de Orientação (CBO, 2008) discorre que:

Como produto de turismo a Orientação é uma atividade que promove o deslocamento de pessoas para a prática do lazer e esporte de forma recreacional e competitiva, em ambientes naturais e espaços urbanos, envolvendo emoções e riscos controlados, exigindo o uso de técnicas e equipamentos específicos e a adoção de procedimentos para garantir a segurança pessoal e de terceiros e o respeito ao patrimônio ambiental e sóciocultural. 
Embora não tratado por Swarbrooke et al. (2003), nem pelo MTUR (2008), este assunto pode ser entendido como relacionado às principais características dos novos turistas apontadas anteriormente, sendo possível entender que a orientação também complementa a prática de diversas atividades do Turismo de Aventura. No caso dos destinos inóspitos, o próprio deslocamento, segundo aponta Swarbrooke et al. (2003), pode ser visto como um componente de aventura.

\subsection{POLÍTICAS PÚBLICAS E MARKETING TURÍSTICO}

Farah (2005) remonta à história das políticas públicas para o turismo de aventura no Brasil, criadas em função do desenvolvimento e crescimento da importância da atividade turística para a economia. $\mathrm{O}$ autor cita diversas conquistas gradativas a partir de resultados com alto índice de crescimento, sendo o turismo inserido no quadro de prioridades do governo. Ainda ressalta que em 1999 o turismo de aventura passou a figurar dentro do espaço das políticas públicas, sendo 2001, o ano da execução das primeiras ações voltadas a este âmbito.

Uma política pública pode ser definida como um conjunto de regras e ações desenvolvidas e executadas pelos governos, através de um ideal coletivo, ou mesmo popular. Elas devem ocorrer de forma harmônica, ou seja, intersetorial dentro do poder público, uma vez que buscam um bem comum, abrangendo diversas áreas desse tipo de administração (DIAS, 2003). Beni (2004, p. 127) cita os papéis que o governo deve exercer: "o de coordenar, planejar, legislar e regulamentar, incentivar, [...] e promover". No sentido de relevar essa importância, Silveira, Paixão e Cobos (2006), no estudo sobre a evolução das ações governamentais no turismo, indicam a decorrente dependência que a atividade turística apresenta em relação a essas. Tendo em vista o último tópico ressaltado por Beni (2000, p. 127), dentre os papéis que um governo deve exercer, entende-se por promoção:

A promoção turística é um item do composto de marketing que abrange todas as ferramentas mercadológicas utilizadas para estabelecer comunicação com o mercado, incluindo as técnicas a serem aplicadas para promover o produto turístico e a forma como a promoção será transmitida ao consumidor. (MTUR, 2007) 
Analisando do ponto de vista do marketing, a promoção pode ser entendida como um dos quatro elementos do mix de marketing, sendo os outros três: produto, preço e praça (distribuição). O item em discussão contempla as “[...] ferramentas de comunicação que fazem chegar uma mensagem ao público-alvo" (KOTLER, 1999, p. 136). Por sua vez, o marketing é definido por Middleton (2002) como um processo de gerenciamento para prestadores de serviços ou produtores, junto ao cliente, buscando atender os desejos e necessidades desse consumidor.

Desde a evolução de estudos de marketing e planejamento estratégico, sempre houve uma ênfase no contexto empresarial. A partir da década de 90, começaram a surgir estratégias e um novo enfoque atendendo também outros tipos de organização, inclusive instâncias públicas locais. Enquanto em outros momentos o esforço promocional de um município esteve voltado somente para oficinas de turismo, atualmente existe o conceito de "Marketing de Lugares", potencializando os locais através da colaboração entre o governo, o poder privado e organizações da sociedade. Essa estratégia pode culminar na atração de mais turistas, novos residentes e ainda investimentos (CARMONA, 2004).

Em concordância, Cobra (2001, p. 404) aponta o marketing competitivo como uma forma de contribuição para desenvolvimento de uma cidade. Ele ressalta: "O papel do marketing é promover a cidade [...]. Para promover o esforço de marketing, a cidade, por meio de sua Secretaria de Turismo e outros, deve investir na formulação de um Plano de Marketing". Ele explica que esse plano deve contemplar um diagnóstico da atividade turística, culminando na elaboração de documentos ou diretrizes norteadoras, como um plano de comunicação e estratégia de produtos. É de seu entendimento também, que todo o processo deve ser formado pela ação conjunta entre a iniciativa pública e a privada.

Em documento do MTUR (2007), concernente ao Programa de Regionalização do Turismo pode-se identificar que se acatam como instrumentos de promoção turística os materiais de apoio (mídias impressas e digitais, com detalhamento e identidade visual), a participação em eventos, rodadas de negócios, propaganda e marketing eletrônico. Sobre o último, é tratado como uma importante ferramenta de promoção, e, embora recente, retrata que se estabeleceu como um dos mais penetrantes e poderosos meios de comunicação direta nos indivíduos. Através dele as informações podem ser 
fornecidas das mais diversas formas: conteúdo, características e qualidades dos produtos e serviços; uso de recursos como som, vídeo e fotos.

No mesmo documento do MTUR (2007) se explicam as competências e funções dentro da promoção de roteiros turísticos. Indica que aos órgãos oficiais de turismo dos estados e às instâncias municipais e regionais, cabem induzir e apoiar o processo de promoção dos produtos de uma região turística, trabalhar de forma cooperativa entre os diversos atores, fornecer informações turísticas (no caso do município a ele cabe levantar essas informações) e participar da elaboração de planos estratégicos e de marketing dos roteiros e da região.

Arruda e Pimenta (2005, p. 55) situam que: “o marketing turístico através dos meios da Internet serão peças fundamentais para a sustentação de qualquer projeto turístico". Os autores entendem que as possibilidades comunicacionais da rede permitem o alcanço de um número grande de consumidores, mas não sendo essa uma forma de divulgação em massa. Mota $\left(2001^{3}\right.$, apud ARRUDA; PIMENTA, 2005) complementa a afirmação, explicando que os recursos multimídia e as telecomunicações, permitem uma nova forma de apresentação de produtos, de melhor qualidade e com grande abrangência mais customizada (não de massa).

\subsection{TURISMO E TECNOLOGIA}

O processo de desenvolvimento de tecnologia da informação e comunicação para o turismo pode ser entendido através da colocação de O'Connor (2001), em que a informação é vista como a "força vital" para a "indústria do turismo", uma vez que os clientes precisam dela para se planejar e optarem pela compra de um produto ou serviço, sendo esses caracterizados pela intangibilidade, fator que atenua a necessidade de informação. As fontes sempre foram diversas, constituídas tanto por empresas (principalmente agências) como por organizações públicas, sendo costumeiro o uso de folhetos ou listas publicadas em guias locais e regionais. Esse processo é visto como dispendioso financeiramente, pela grande necessidade de impressão, apontando a carência de otimização na troca de informações, tanto com relação à velocidade quanto aos custos. A tecnologia da informação surge da estrutura da computação, comunicação

\footnotetext{
${ }^{3}$ MOTA, Keila Cristina Nicolau. Marketing turístico: promovendo uma atividade sazonal. São Paulo: Atlas, 2001.
} 
e eletrônica, como característica universal do turismo, transportando informações quase que instantaneamente para todo o mundo.

Arruda e Pimenta (2005) apontam as tecnologias digitais de informação e comunicação como recursos de grande poder para o desenvolvimento do mercado turístico. Eles indicam que o consumidor tem cada vez mais acesso às informações de seu objeto de turismo, cabendo aos profissionais da área assegurar qualidade nas áreas de exibição, como em sites.

Sant'anna e Jardim (2007, p. 3) entendem a Interner como “[...] uma das principais tecnologias de informação e comunicação. [...] permitindo a troca de dados e informações disponibilizados em uma ampla rede". O'Connor (2001) aponta que são diversas as aplicações da Internet e é difícil conseguir avaliar o impacto na atividade, em função de um rápido crescimento onde as pesquisas se apresentam sempre defasadas. Ele afirma ainda que isso não simboliza um crescimento positivo, uma vez que ainda existem deficiências na rede, como por exemplo, a dificuldade de associar aquilo que se busca com resultados.

O'Connor (2001) entende ainda que o papel dos órgãos públicos nesse processo é o de ajudar pequenas e médias empresas, através de uma promoção ativa. O poder público é fundamental como base de informações aos turistas, incluindo atrativos, transporte público, ambiente e exigências legais. Esse banco de dados é entendido como um dos mais importantes, uma vez que com grande chance o turista irá buscar as informações nos canais de organismos oficiais. Há, portanto, uma preocupação com a qualidade dos dados, que devem ser precisos e atualizados.

\subsection{INFORMAÇÃO ESPACIAL: GEOPROCESSAMENTO E OS APARELHOS DE GPS}

A geotecnologia é considerada por Neves (2006), como um conjunto de ferramentas indispensáveis para o planejamento e gestão de atividades de ecoturismo em ambientes naturais. No entendimento da autora, o crescimento desse tipo de turismo evidencia uma necessidade de se estabelecer uma relação entre planejamento turístico e conservação do espaço, sendo algumas das ferramentas para tal finalidade: "Sistema de Informação Geográfica (SIG), Global Positioning System (GPS), Sensoriamento 
Remoto (SR), Processamento Digital de Imagem (PDI), Banco de Dados Geográficos (BDG) [...]”. Goés et al. (2004, p. 116) complementam a afirmação, citando que “[...] as novas tecnologias de manuseio da informação espacial podem ser uma resposta à gestão municipal, pois subsidiam o processo de decisão com informações sobre o território". Os autores entendem que as ferramentas descritas por Neves (2006) servem de subsídio para a criação de um Sistema de Informações Espaciais, um “[...] ambiente de respostas a perguntas que envolvem o fator localização" (GOÉS et al., 2004, p. 116).

Barbosa (2005, p. 57) considera como geotecnologia “[...] o conjunto de ferramentas e materiais utilizados no auxílio de análises de informações espaciais”. O autor explica que esse termo teve origem na manipulação de informações especializadas. Se por um lado os autores usam a geotecnologia para as ferramentas, Silva (2001 ${ }^{4}$, apud VEIGA; SILVA. In: SILVA; ZAIDAN, 2004, p. 12) define geoprocessamento como sendo:

[...] um conjunto de técnicas computacionais que opera sobre base de dados (que são registros de ocorrências) georreferenciados, para transformar a informação (que é um acréscimo de conhecimento) relevante, deve necessariamente apoiar-se em estruturas de percepção ambiental que proporcionem o máximo de eficiência nessa transformação.

Alguns pesquisadores "lançam mão" do geoprocessamento para o planejamento e gestão da atividade turística regional e municipal. Veiga e Silva (In: SILVA; ZAIDAN, 2004) utilizaram um conjunto de técnicas para avaliar a potencialidade turística de regiões em Macaé - RJ, através do uso de SGI (Sistema Geográfico de Informação), com o cruzamento de diversos dados sobre o município como saneamento, demografia e qualidade de vida. Bueno (In: QUEVEDO, 2007) usou o geoprocessamento através de um SGI, inserindo informações institucionais e também coleta em campo com a ferramenta GPS, visando utilizar a "Geoinformação" nas atividades de Ecoturismo.

Esses dados empregados no geoprocessamento podem ser coletados de diversas formas, inclusive através de registro público e de institutos de pesquisa (BUENO. In: QUEVEDO, 2007) e Veiga e SILVA (In: SILVA; ZAIDAN, 2004). Se por um lado alguns são de alta complexidade de obtenção, conforme afirma Neves (2006), outros

\footnotetext{
${ }^{4}$ SILVA, Jorge Xavier da. Geoprocessamento para análise ambiental. Rio de Janeiro: J. Xavier da Silva, 2001.
} 
podem ser facilmente coletados, até em atividades de lazer: "[...] o GPS é utilizado na atividade turística principalmente na navegação, nos espaços naturais desprovidos de trilhas, no mapeamento de trilhas e na localização de pontos de interesse turístico." (NEVES, 2006, p. 639). Esse universo de dados pode ser portado para outros sistemas (para SIG's por exemplo) e tratados, de forma a gerar informações para fins de pesquisa ou outras aplicações.

Letham (2001) cita três benefícios pessoais agregados a um GPS: guiar alguém até um destino contido num mapa, calcular sua posição atual e registrar sua posição inicial para um possível retorno ao mesmo ponto da Terra posteriormente. O mesmo autor entende que o emprego desse aparelho no lazer pode ser altamente atrativo, citando alguns exemplos: excursionismo (chance de se perder em uma caminhada é muito menor, pela precisão do aparelho), viagem de carro (orientação em qualquer via), rally (orientação em trilhas), viagens em caiaque ou canoa (orientação em rios), entre outros.

Featherstone (2004) explica que os mapas e dados do aparelho podem ser compartilhados pela Internet, através da conectividade com um computador. Se por um lado o aparelho já sai da fábrica com mapas básicos, é possível adquirir outros mapas e conjuntos de dados de acordo com as necessidades de cada um, como por exemplo: turistas (informações sobre atrativos urbanos, city-tours, monumentos); excursionistas (lagos, cachoeiras, montanhas, trilhas). Esses dados podem ser trocados entre usuários ou mesmo comercializados.

\section{METODOLOGIA E INSTRUMENTOS DE COLETA DE DADOS}

A presente pesquisa possui caráter exploratório, uma vez que visa aumentar a experiência e o conhecimento sobre um problema, no caso, a relação que os usuários dos aparelhos de GPS estabelecem entre a visitação e a promoção de um destino turístico. Para tanto, foi utilizado o método qualitativo, caracterizado pela obtenção de dados de observação ou mesmo de documentos e audiovisuais, análise de texto e de imagem. Neste caso, "o pesquisador coleta dados emergentes abertos com o objetivo principal de desenvolver temas a partir dos dados" (CRESCHEL, 2007, p. 35). 
A pesquisa foi dividida em três etapas. Na primeira delas, utilizou-se de fontes bibliográficas, processo visto como imprescindível para qualquer pesquisa científica, incluindo ainda nos seus objetivos a análise sobre as principais contribuições a respeito de algum fato, assunto ou idéia (SANTOS, 2002).

No segundo momento, foi efetuada uma busca por ambientes virtuais onde houvesse o compartilhamento de arquivos originados de GPS, com o intuito de descobrir quais eram os principais formatos utilizados para disponibilizar aos usuários as informações necessárias à navegação com os aparelhos, ou interpretação por outros softwares ou websites. Os critérios para definição dos websites foram: possibilidade de importação para aparelhos GPS, sendo portais na Internet, com acesso livre, caráter gratuito, representação do ambiente natural e geridos no Brasil. Para enumeração foi efetuada a pesquisa nos três principais motores de busca na Internet no mundo: Google Sites, Microsoft Sites e Yahoo Sites (COMSCORE, 2008), com a soma das palavraschave envolvendo os formatos estudados.

Em cada um dos seis websites encontrados a partir dos resultados das buscas acima citadas, foi efetuada nova busca (dentre os seis) identificando os formatos de arquivos utilizados para a disponibilização aos usuários. Posto isso, o instrumento de coleta de dados nesta fase foi somente a observação.

Observações [...] o pesquisador registra de forma estruturada ou semiestruturada [...] as atividades no local da pesquisa [...] os papéis podem variar de pesquisador não participante até integralmente participante. [...] (CRESCHEL, 2007, p. 190)

Em seguida foram selecionados três formatos, pelo número de ocorrências nos seis websites, sendo este o subsídio da fase seguinte que se constituiu em uma pesquisa documental. Nessa ocasião buscou-se compreender e enumerar as propriedades de cada um desses três formatos, visando identificar de que forma eles iriam se alinhar aos requisitos necessários para a promoção de um roteiro/destino turístico, seguindo as orientações práticas encontradas em documento do MTUR (2007) e em BAHL (2004).

O modelo de avaliação estabelecido é exibido no Quadro 1. 


\begin{tabular}{|l|l|l|l|}
\hline \multicolumn{1}{|c|}{ Quesito Avaliado } & \multicolumn{2}{c|}{ Formatos } \\
\hline Título / Nome do roteiro / País de origem / Estado & & & \\
\hline Descrição do roteiro (incluindo municípios contemplados) & & & \\
\hline $\begin{array}{l}\text { Atrativos a serem visitados (fotos, localização, dias e horários para visitação, } \\
\text { aspectos culturais e ambientais, gastronomia típica, peculiaridades e curiosidades) }\end{array}$ & & & \\
\hline Segmento turístico comtemplado / Direcionamento público-alvo & & & \\
\hline Distâncias & & & \\
\hline Caminho a percorrer & & & \\
\hline Quilometragem & & & \\
\hline Número de paradas & & & \\
\hline Transporte (automóvel, ônibus, outros) & & & \\
\hline Duração & & & \\
\hline Locais de chegada e saída & & & \\
\hline Mapa turístico do roteiro & & & \\
\hline Contatos para a comercialização & & & \\
\hline Contatos institucionais & & & \\
\hline Custos (preço para a visitação) & & & \\
\hline Alojamento (categoria, valores, informações gerais sobre os empreendimentos) & & & \\
\hline Alimentação (localização, categoria, contatos) & & & \\
\hline
\end{tabular}

QUADRO 1 - MODELO DE ANÁLISE COMPARATIVA: ROTEIROS E PROPRIEDADES DOS FORMATOS DO GPS

FONTE: BETTONI, E. M. (2008) baseado em BAHL (2004) e MTUR (2007).

Notou-se em MTUR (2007) um aprofundamento na identificação e potencialização de atrativos, com a finalidade de organizar o processo de roteirização com grande ênfase à oferta turística, aos destinos -, enquanto Bahl (2004) revela uma sistemática mais ampla, tanto de âmbito privado quanto institucional (pública), considerando a montagem de roteiros também pela visão de operação e comercialização dos mesmos (cita, por exemplo, a elaboração de um programa). Ambos tratam sobre a promoção turística de roteiros, sendo um com foco maior em produtos integrados desde uma base local até internacional (BAHL, 2004) e outro na institucionalização regional do roteiro no contexto brasileiro (MTUR, 2007). Posto isso, a análise dos formatos de arquivos de GPS se deu em comparação com um modelo de promoção turística, instituído pelo cruzamento entre a teoria fornecida nas duas publicações.

A análise final do trabalho compreendeu a verificação da possibilidade do uso dos formatos de arquivo GPS como ferramenta para a promoção, através da adaptação de suas atribuições no sentido de agregar todas ou parte daquelas informações julgadas como essenciais na concepção do documento do MTUR (2007) e ainda no de Bahl (2004). 


\section{APRESENTAÇÃO E ANÁLISE DOS RESULTADOS}

Neste tópico são apresentados os resultados da coleta de dados, que foi dividida em três etapas: levantamento bibliográfico e dos sites, através das pesquisas nos motores de busca e também em bibliografia relacionada; a definição de formatos, no que tange a seleção dentre os resultados da primeira fase de um universo a ser tratado e, por fim, uma análise de acordo com as especificações técnicas de cada formato e o conteúdo relacionado aos roteiros turísticos.

\subsection{LEVANTAMENTO BIBLIOGRÁFICO E DOS SITES}

Sendo a primeira fase da pesquisa conhecida como bibliográfica e documental, os resultados apresentados foram descritos e acrescentados à visão teórica, com o intuito de aprofundar e explorar o conhecimento com relação à área da pesquisa, gerando subsídios para as considerações finais e ainda para análise de outros dados coletados.

A segunda etapa da pesquisa compreendeu a busca na Internet dos sites que disponibilizassem arquivos geoprocessados para o uso em atividades de lazer (não profissional), no formato de compartilhamento, sendo encontrados apenas seis websites com as características propostas na metodologia. No Quadro 2 foram indicados os sites e a respectiva sessão onde as informações foram encontradas e também se convencionou classificá-los por ordem alfabética para facilitar a análise posterior de resultados (letras de "A" até "F").

$\mathrm{Na}$ observação dos websites, foram analisadas as formas como os usuários poderiam interagir com eles, de maneira a inserir informações oriundas dos seus aparelhos de GPS, ou adquirir de forma gratuita, os dados disponibilizados online por outros usuários ou pelos gestores do website.

\begin{tabular}{|l|l|l|}
\hline & \multicolumn{1}{|c|}{ Título / Endereço } & \multicolumn{1}{|c|}{ Sessão } \\
\hline A & Webventure - http://www.webventureuol.uol.com.br & Onde praticar \\
\hline B & Sigatrilha - http://www.sigatrilha.com.br & Trajetos \\
\hline C & Adventuremag - http://www.adventuremag.com.br & GPS Track \\
\hline D & Projeto Track Source - http://www.tracksource.org.br & Downloads \\
\hline E & Geobusca - http://www.geobusca.net & Colaboração \\
\hline F & Pedal - http://www.pedal.com.br & Trilhas \\
\hline
\end{tabular}

QUADRO 2 - WEBSITES ANALISADOS NA SEGUNDA ETAPA.

FONTE: BETTONI, E. M. (2008). 
No caso dos sites "B" e "C" notou-se que não havia possibilidade de interação dos usuários, sendo somente uma forma de divulgação dos roteiros de turismo de aventura e ecoturismo levantados pelos criadores, com fins de disponibilizar para outras pessoas interessadas.

Ao contrário desse posicionamento, os sites "A", "E" e "F" foram considerados como de alta interatividade, uma vez que foram criados e são mantidos pelos usuários, e não pela organização mantenedora dos websites. Em todos os casos houve necessidade de cadastro prévio para a postagem de arquivos para GPS, sendo o serviço gratuito e não existindo funções restritivas por esse motivo. Neste caso, notou-se a heterogeneidade das informações disponibilizadas, incluindo desde roteiros históricoculturais, até sobre o próprio turismo de aventura, que foi a proposta da análise.

O site "D" pôde ser julgado como diferenciado dos dois outros grupos, pela sua característica de formação. Trata-se de uma página da Internet de um projeto de colaboração entre usuários para a criação e atualização de mapas do Brasil e outras localidades, com foco nos modais de transporte (malha viária, ferroviária, aérea), sem abordar atrativos e outros pontos de interesse. Ainda assim, mostrou-se pertinente, uma vez que o projeto trabalha com ideal associativista para a formatação de dados de orientação, muitas vezes podendo ser usados pelos turistas.

\subsection{DEFINIÇÃO DOS FORMATOS}

O objetivo principal desta etapa foi identificar em cada um dos sites, os tipos (formatos) de arquivos utilizados no intercâmbio de informações para posterior importação ao aparelho de GPS; nesse sentido, os resultados são apresentados no Quadro 3.

\begin{tabular}{|c|l|}
\hline Sites & \multicolumn{1}{|c|}{ Formato de Arquivo Utilizado } \\
\hline A & KML (Keyhole Markup Language), GPX (GPS Exchange Format) \\
\hline B & GTM (Gps Track Maker) \\
\hline C & KMZ/KML (Keyhole Markup Language) \\
\hline D & GTM (GPS Track Maker) \\
\hline E & $\begin{array}{l}\text { GTM (GPS Track Maker), GPX (GPS Exchange Format), KMZ/KML (Keyhole Markup } \\
\text { Language) }\end{array}$ \\
\hline F & KML (Keyhole Markup Language) \\
\hline
\end{tabular}

QUADRO 3 - FORMATO DE ARQUIVO UTILIZADO

FONTE: BETTONI, E. M. (2008). 
Com a apresentação dos resultados acima, optou-se por utilizar quatro formatos diferentes de arquivos, contendo informações originadas pelos GPS ou que podiam ser inseridas nesses aparelhos: GTM, GPX, KML e KMZ, conforme justificativa abaixo.

O software gratuito "Gps Track Maker" (GTM) é visto como uma das principais aplicações, no Brasil, para a manipulação de dados obtidos através de GPS (GEOBUSCA, 2008; PORTALGPS, 2008; INFOEXAME, 2008). O formato padrão de gravação utilizado possui a extensão GTM, que permite o armazenamento de waypoints ${ }^{5}$ tracks $^{6}$, rotas, imagem de fundo, texto para waypoints, textos definidos pelo usuário e imagens digitalizadas (GPS TRACKMAKER, 2008).

O formato GPX é a abreviatura de GPS Exchange Format. Este modelo foi criado em código aberto (para fins de desenvolvimento público), baseando-se em XML, com a finalidade de facilitar o intercâmbio entre dados (waypoints, rotas e tracks) de GPS entre aplicativos e sites na Internet (TOPOGRAFIX, 2008).

Os formatos KML e KMZ são semelhantes, sendo que o segundo é somente um modelo compactado do primeiro. O KML (Keyhole Markup Language) é originado da empresa Keyhole, atualmente sob o domínio do Google, através das aplicações "Google Earth" e "Google Maps". A sua importância se dá pela popularidade dos dois aplicativos baseados em informações da Internet citados, sendo o primeiro líder de popularidade na categoria de simuladores do globo virtual, com imagens de satélites, mapas e terrenos disponíveis gratuitamente (GOOGLE CODE, 2008).

\subsection{ANÁLISE COMPARATIVA: ROTEIROS E PROPRIEDADES DOS FORMATOS DO GPS}

O objetivo dos idealizadores dos formatos de arquivo geoprocessados é a disponibilização do maior número de informações possíveis, para serem gravadas ou extraídas de aparelhos de GPS, atingindo o usuário final. Neste caso, entende-se que se trata de uma construção totalmente voltada à orientação espacial, não necessariamente atrelada à atividade turística, conforme o proposto nesta pesquisa. Mesmo assim, foram

\footnotetext{
5 Waypoints: são coordenadas de uma posição (latitude e longitude) no mundo. Os dados podem ser armazenados, gravados e transferidos pelos aparelhos de GPS (BROIDA, 2004).

${ }^{6}$ Track: é uma seqüência de marcações (através de coordenadas de latitude de longitude) deixadas quando se percorre um espaço com o GPS (com esse recurso ativado), formando um caminho que pode ser percorrido novamente apenas seguindo essa marcação anterior (BROIDA, 2004).
} 
apontados diversos recursos nos seus formatos que com adaptações, podem vir a suprir o quadro de necessidades na perspectiva de promoção turística adotada. Os resultados estão representados no Quadro 4.

De um total de dezessete quesitos avaliados, percebeu-se que em nenhum deles a capacidade de portar informações georeferenciadas dos arquivos foi ineficaz totalmente. Aquele que esteve mais distante, sob essa perspectiva, foi o da distinção de tipos de transporte, sendo que os formatos GPX e KML/KMZ não permitem esclarecer ou representar o tipo de transporte. Ainda que essa limitação seja suprimida no GTM, os formatos anteriores permitem ao usuário ter o acesso à velocidade média exata durante cada um dos pontos de um trajeto, o que pode servir de pressuposto para a distinção do transporte utilizado (exemplo: em se tratando de uma estrada em más condições, é provável que um ônibus não consiga atingir uma velocidade média de setenta quilômetros horários). Posto isso, o usuário do GPS terá uma noção preliminar com relação ao transporte a ser utilizado.

Entende-se como outro fator decisório nos resultados, a possibilidade de um campo aberto para inserir "outras informações", que serviu como adaptação para a inclusão de informações como a descrição de atrativos, os preços de entrada, a classificação da infra-estrutura turística (alojamento de alimentação), os dias e horários para visitação e outras peculiaridades. Ainda que não existam campos específicos para cada categoria, os arquivos não inibem a exibição dessas informações, desde que estruturadas pelos próprios usuários. O único formato que apresentou restrição neste caso foi o GPX, que não possibilitou a descrição dos pontos georreferenciados ou acréscimo de outras informações.

\begin{tabular}{|l|l|l|l|}
\hline \multicolumn{2}{|c|}{ Quesito Avaliado } & \multicolumn{3}{c|}{ Formatos } \\
\cline { 2 - 4 } & \multicolumn{1}{|c|}{ GTM } & \multicolumn{1}{c|}{ GPX } & \multicolumn{1}{c|}{ KML/KMZ } \\
\hline $\begin{array}{l}\text { Título / Nome do roteiro / País } \\
\text { de origem / Estado }\end{array}$ & $\begin{array}{l}\text { Nome do arquivo, } \\
\text { Referência de } \\
\text { localização. }\end{array}$ & $\begin{array}{l}\text { Nome do arquivo, } \\
\text { Referência de } \\
\text { localização. }\end{array}$ & $\begin{array}{l}\text { Nome do arquivo, } \\
\text { Referência de } \\
\text { localização. }\end{array}$ \\
\hline $\begin{array}{l}\text { Descrição do roteiro (incluindo } \\
\text { municípios contemplados) }\end{array}$ & $\begin{array}{l}\text { Possibilidade de inserir } \\
\text { textos em qualquer } \\
\text { lugar da representação }\end{array}$ & $\begin{array}{l}\text { Está limitado quanto ao } \\
\text { número de caracteres, } \\
\text { não pode agregar texto. }\end{array}$ & $\begin{array}{l}\text { Há espaço para } \\
\text { descrição com } \\
\text { formatação } \\
\text { aprimorada }\end{array}$ \\
\hline Atrativos a serem visitados & $\begin{array}{l}\text { Há possibilidade de } \\
\text { inserção de fotos, a }\end{array}$ & $\begin{array}{l}\text { Há possibilidade de } \\
\text { inserir a localização }\end{array}$ & $\begin{array}{l}\text { Há possibilidade de } \\
\text { inserir localização }\end{array}$ \\
\hline
\end{tabular}

\footnotetext{
${ }^{7}$ Análise com base em arquivos obtidos em sites pesquisados e na documentação (GPS TRACKMAKER, 2008; TOPOGRAFIX, 2008; GOOGLE CODE, 2008)
} 


\begin{tabular}{|c|c|c|c|}
\hline \multirow[t]{2}{*}{ Quesito Avaliado } & \multicolumn{3}{|c|}{ Formatos $^{7}$} \\
\hline & GTM & GPX & KML/KMZ \\
\hline $\begin{array}{l}\text { (fotos, localização, dias e } \\
\text { horários para visitação, } \\
\text { aspectos culturais e ambientais, } \\
\text { gastronomia típica, } \\
\text { peculiaridades e curiosidades) }\end{array}$ & $\begin{array}{l}\text { localização é } \\
\text { georreferenciada e é } \\
\text { possível incluir outras } \\
\text { informações. }\end{array}$ & $\begin{array}{l}\text { georreferenciada, mas } \\
\text { sem maiores } \\
\text { informações, somente } \\
\text { ícones. }\end{array}$ & $\begin{array}{l}\text { georreferenciada, } \\
\text { informações } \\
\text { detalhadas e links para } \\
\text { sites, além de ícones. }\end{array}$ \\
\hline $\begin{array}{l}\text { Segmento turístico } \\
\text { contemplado / Direcionamento } \\
\text { público-alvo }\end{array}$ & $\begin{array}{l}\text { Pode ser contemplado } \\
\text { pelo uso de ícones. }\end{array}$ & $\begin{array}{l}\text { Pode ser contemplado } \\
\text { pelo uso de ícones. }\end{array}$ & $\begin{array}{l}\text { Pode ser contemplado } \\
\text { pelo uso de ícones. }\end{array}$ \\
\hline Distâncias & $\begin{array}{l}\text { Precisa, através de } \\
\text { georreferência. }\end{array}$ & $\begin{array}{l}\text { Precisa, através de } \\
\text { georreferência. }\end{array}$ & $\begin{array}{l}\text { Precisa, através de } \\
\text { georreferência. }\end{array}$ \\
\hline Caminho a Percorrer & Idem & Idem & Idem \\
\hline Quilometragem & Idem & Idem & Idem \\
\hline Número de paradas & Através de pontos & Através de pontos & Através de pontos \\
\hline $\begin{array}{l}\text { Transporte (automóvel, ônibus, } \\
\text { outros) }\end{array}$ & $\begin{array}{l}\text { Pode ser distinguido } \\
\text { pela formatação do } \\
\text { arquivo. }\end{array}$ & Não há distinção. & $\begin{array}{l}\text { Pode ser indicado, } \\
\text { mas não há distinção. }\end{array}$ \\
\hline Duração & $\begin{array}{l}\text { Cálculo preciso do } \\
\text { tempo total }\end{array}$ & $\begin{array}{l}\text { Cálculo preciso do } \\
\text { tempo total }\end{array}$ & $\begin{array}{l}\text { Cálculo preciso do } \\
\text { tempo total }\end{array}$ \\
\hline Locais de chegada e saída & Através de pontos & Através de pontos & Através de pontos \\
\hline Mapa turístico do roteiro & $\begin{array}{l}\text { Representação de } \\
\text { caminhos, pontos }\end{array}$ & $\begin{array}{l}\text { Representação de } \\
\text { caminhos, pontos }\end{array}$ & $\begin{array}{l}\text { Representação de } \\
\text { caminhos, pontos }\end{array}$ \\
\hline $\begin{array}{l}\text { Contatos para a } \\
\text { comercialização }\end{array}$ & $\begin{array}{l}\text { Possibilidade de inserir } \\
\text { textos em qualquer } \\
\text { lugar da representação }\end{array}$ & $\begin{array}{l}\text { Está limitado quanto ao } \\
\text { número de caracteres, } \\
\text { não pode agregar texto. }\end{array}$ & $\begin{array}{l}\text { Há espaço para } \\
\text { descrição com } \\
\text { formatação } \\
\text { aprimorada }\end{array}$ \\
\hline Contatos institucionais & Idem & Idem & Idem \\
\hline Custos (preço para a visitação) & Idem & Idem & Idem \\
\hline $\begin{array}{l}\text { Alojamento (categoria, valores, } \\
\text { informações gerais sobre os } \\
\text { empreendimentos) }\end{array}$ & $\begin{array}{l}\text { Através de pontos, com } \\
\text { indicação de sites e } \\
\text { outras informações }\end{array}$ & $\begin{array}{l}\text { Através de pontos sem } \\
\text { maiores informações }\end{array}$ & $\begin{array}{l}\text { Através de pontos, } \\
\text { com indicação de sites } \\
\text { e outras informações }\end{array}$ \\
\hline $\begin{array}{l}\text { Alimentação (localização, } \\
\text { categoria, contatos) }\end{array}$ & Idem & Idem & Idem \\
\hline \multirow[t]{3}{*}{ Legenda: } & \multirow{2}{*}{\multicolumn{2}{|c|}{\begin{tabular}{|l|} 
Formato contempla o quesito \\
\end{tabular}}} & \\
\hline & & & \\
\hline & \multicolumn{2}{|c|}{ Formato não contempla o quesito } & \\
\hline
\end{tabular}

QUADRO 4 - ANÁLISE COMPARATIVA: ROTEIROS E PROPRIEDADES DOS ARQUIVOS DE GPS

FONTE: BETTONI, E. M. (2008).

Ainda que para a classificação das "outras informações", os arquivos possam ser considerados desestruturados, ao se tratar da precisão nos detalhes que concernem ao itinerário e representação, de maneira geral, o destaque e a superioridade dos dados é um ponto favorável. Nos itens "Distância", "Caminho a percorrer", "Quilometragem", "Número de paradas", "Duração", "Locais de chegada e saída" e "Mapa turístico do 
roteiro", ressaltou-se a capacidade precisa dos dados fornecidos por georreferência, proporcionando uma visão espacial realista àqueles que se utilizam desses arquivos, na coleta de informações através de diversas coordenadas. Em função das suas aplicações técnico-científicas, essas informações são de grande confiabilidade, favorecendo ainda mais as perspectivas de orientação pelos turistas que venham a utilizá-las.

Um quarto e último destaque para os formatos dos arquivos se refere aos ícones disponíveis para denominação de determinados pontos. Nos casos do GTM e GPX há uma semelhança maior (e compatibilidade) dos ícones utilizados, sendo que, a maioria das categorias de serviços e infra-estrutura empregadas no turismo possui uma variedade de denominações (exemplos: hospedagem simples, atrativo cultural, automecânica, entre outros). Ainda que o KML/KMZ seja destoante aos outros dois quanto à padronização, também disponibilizou diversos ícones para a indicação de hospedagem, alimentação, pontos de interesse e alimentação. Uma representação de alguns ícones pode ser vista na Figura 1.

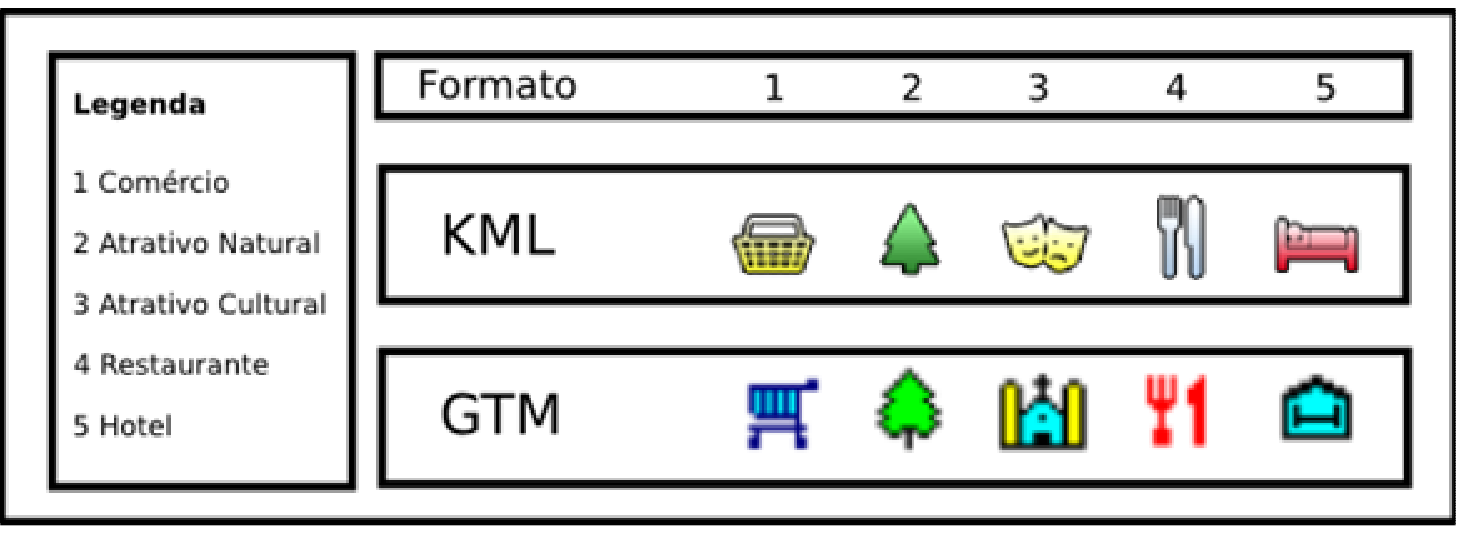

FIGURA 1 - DIFERENTES REPRESENTAÇÕES DE ÍCONES NOS FORMATOS KML E GTM FONTE: BETTONI, E. M. (2008).

Com relação à utilização dos formatos, esclarece-se que o GTM foi aquele que melhor atendeu aos requisitos propostos, sendo entendido como o ideal para o uso na promoção turística, conforme proposto na metodologia. Porém, outro fator ainda deve ser analisado no seu emprego. Ao contrário dos outros, só pode ser interpretado depois da instalação de um software, com foco em usuários muito experientes. Segundo essa suposição, o investimento na promoção turística estaria muito focalizado (usuários de GPS muito experientes) ao invés de exercer sua função proposta. Em contraposição a 
isso, os formatos GPX e KML/KMZ podem ser representados através de páginas na Intenet, sem necessidade de pagamento pelo serviço ou instalação de algum software, como ocorre com a ferramenta Google Maps. Neste serviço, um usuário comum pode inserir ou exibir os arquivos gerados (GPX, KML/KMZ) junto a um de terreno ou com imagens de satélite. Desta forma, entende-se que está mais alinhado às políticas públicas, já que abrange também um público-alvo leigo com aparelho de GPS.

\section{CONSIDERAÇÕES FINAIS}

A proposta da pesquisa relatada neste artigo foi a de verificar se o compartilhamento de dados dos usuários de aparelhos de GPS em atividades de lazer poderia contribuir de alguma forma para a promoção de um destino turístico. Posto isso, se fez fundamental compreender onde ocorriam essas trocas e qual o tipo de informações que circulavam nessas situações. Da compreensão desse fator, partiu-se para o entendimento da potencialidade atrelada ao conteúdo possível de ser gravado, sob o prisma da roteirização turística.

O número de websites que já disponibilizam formatos de intercâmbio foi percebido como inexpressivo no Brasil, principalmente no que se refere ao seu manuseio por usuários inexperientes que estejam começando a utilizar o GPS com fins de lazer. Essa comprovação contraria as tendências de crescimento desse nicho de mercado, mencionadas anteriormente.

Notou-se uma dicotomia expressiva entre os websites que disponibilizam os arquivos para download, compreendendo desde grandes projetos para usuários muito experientes, quanto de interfaces gráficas para edição e elaboração de roteiros por leigos.

Nos modelos "A" e "E" foram encontrados espaços para interação daqueles que sequer possuem GPS, porém, com conhecimento prévio da área, podem vir a se localizar somente com o cruzamento entre as georreferências de outros usuários e pontos conhecidos (por exemplo, uma igreja, um mercado, uma praça, um indicação de encruzilhada). Essa representação pode ser vista na Figura 2. 


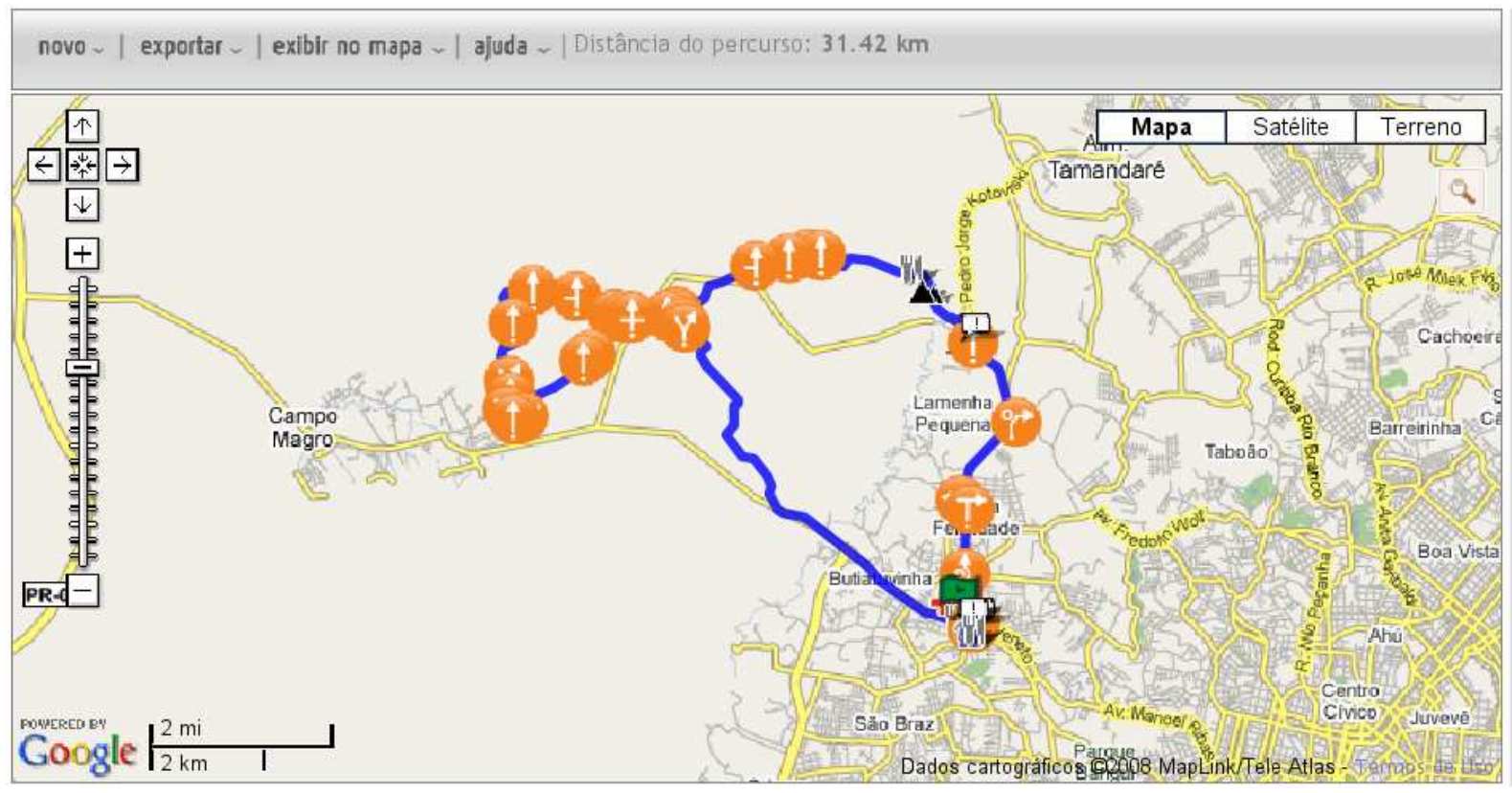

FIGURA 2 - REPRESENTAÇÃO PARA USUÁRIOS QUE NÃO POSSUEM GPS

FONTE: BETTONI, E. M. com base em WEBVENTURE (2008).

O universo definido pode ter restringido resultados importantes, talvez por uma falha de posicionamento de sites em relação aos buscadores, o que instigaria o aprofundamento através de uma nova pesquisa, considerando critérios de maior amplitude, inclusive em nível internacional. Uma comprovação desse fato ocorreu durante as buscas, quando muitas vezes eram exibidas páginas com idioma "Português", mas de origem portuguesa e não brasileira. Nos muitos websites exibidos, havia especialização em turismo, com caráter de rede social onde os usuários poderiam inserir suas tracks de GPS para poder compartilhar com os outros. Ainda que não pertencente à abordagem da pesquisa, a constatação serviu como base para compreender que as tendências levantadas já estão sendo concretizadas em algumas nações, principalmente as européias.

Uma segunda dificuldade percebida na pesquisa, que pode fomentar a continuidade com aprofundamento foi a da ausência de um relacionamento das possibilidades propostas pelos formatos de arquivos GPS, com a real utilização pelos usuários. Buscar-se-ia verificar se há restrição aos recursos básicos, o que demonstraria uma incompatibilidade inicial com a proposta de complementar a promoção turística.

Dos websites pesquisados, não houve representação de qualquer instância pública ou de ligação com a promoção de destinos turísticos, demonstrando, no universo 
proposto, que os recursos ainda não são aproveitados. Com este artigo propôs-se elucidar a potencialidade percebida nessas ações, descentralizadas, de grupos de aventureiros ou websites de referência (característicos dos locais pesquisados), com relação às necessidades percebidas em MTUR (2007) no campo da promoção turística. A precisão de informações e a facilidade com que são intercambiadas, formam um cenário ideal para que sua utilização seja integrada nas políticas públicas, sob a perspectiva da abordagem no marketing turístico, principalmente no que tange às atividades de aventura.

\section{REFERÊNCIAS}

ABI Research. GPS-enabled Handset Market to Generate Over \$100 Billion in Revenues in 2012, 29 nov. 2007. Press Release. Disponível em <http://www.abiresearch.com >. Acesso em: 02/09/2008.

ABREU, J. A.; TIMO, G. Normalização e certificação em turismo de aventura no Brasil. In: UVINHA, R. (Org.). Turismo de aventura: reflexões e tendências. São Paulo: Aleph, 2005, p. 51.

ADVENTUREMAG. GPS Track. Disponível em: <http://www.adventuremag.com.br>. Acesso em: 20/11/2008.

ARRUDA, E.; PIMENTA, D. Algumas reflexões sobre a Internet e as estratégias comunicativas no marketing em Turismo. Caderno Virtual do Turismo: IVT, v. 5, n. 4, 2005. Disponível em: <http://www.dominiopublico.gov.br>. Acesso em: 23/09/2008.

BAHL, M. Viagens e roteiros turísticos. Curitiba: Protexto, 2004.

BARBOSA, A. Subsídios para o planejamento em ecoturismo na região do médio Rio Grande, Minas Gerais, utilizando geoprocessamento e sensoriamento remoto. Dissertação de Mestrado (Programa de Pós-Graduação em Sensoriamento Remoto). São José dos Campos: INPE, 2005.

BELSON, K. Anyone Can Make Maps. New York Times, New York. p. 10, jan. 2008. Disponível em: <https://www.nytimes.com>. Acesso em: 02/09/2008.

BENI, M. Análise estrutural do turismo. São Paulo: Senac, 2004.

BROIDA, R. How to do everthing with you GPS. Emeryville: Mac-hill Osborne Media, 2004. Disponível em: <http:///books.google.com.br>. Acesso em: 09/01/2009. 
BUENO, L. A geoinformação na elaboração de projetos de ecoturismo. In: QUEVEDO, M. Turismo na era do conhecimento. Florianópolis: Pandion, 2007. Disponível em: <http://books.google.com.br>. Acesso em: 01/10/2008.

CARMONA, J. M. L. Planificación estratégia y marketing de lugares. Comunidad Virtual de Gobernabilidad y Liderazgo, Chile, 08/mai./2004. Disponível em: <www.gobernabilidad.cl>. Acesso em: 29/09/2008.

CBO. Institucional. Disponível em: <http://www.cbo.org.br>. Acesso em: 29/09/2008.

COBRA, M. Marketing de turismo. São Paulo: Cobra, 2001.

COMSCORE. Press release: Core sSearch Entity. Disponível em: $<$ http://www.comscore.com>. Acesso em: 12/10/2008.

CRESCHEL, J. Projeto de pesquisa. Porto Alegre: Artmed, 2007

CRUZ, R. Política de turismo e território. São Paulo: Contexto, 2002.

DIAS, R. Planejamento do turismo: política e desenvolvimento do Brasil. São Paulo: Atlas, 2003.

FARAH, S. Políticas de incentivo ao turismo de aventura. In: UVINHA, Ricardo (Org.). Turismo de aventura: reflexões e tendências. São Paulo: Aleph, 2005.

FEATHERSTONE, S. Outdoor guide to using your gps: tips for hikers, campers, hunters, boaters. Creative Publishing international, 2004. Disponível em: <http://books.google.com.br>. Acesso em: 02/09/2008.

FURLAN, S. Ecoturismo: do sujeito ecológico ao consumidor da natureza. In: RODRIGUES, A. (Org.). Ecoturismo no Brasil: possibilidades e limites. São Paulo: Contexto, 2003.

GEOBUSCA. Sobre o geobusca. Disponível em: <http://www.geobusca.net>. Acesso em: 29/09/2008.

GPS TRACKMAKER. Características. Disponível em: <http://www.gpstm.com>. Acesso em: 20/11/2008.

GÓES, M.; XAVIER, J.; PEREIRA, E. R.; OLIVEIRA, W. J. O caso do município de Linhares. In: SILVA, J. ZAIDAN, R. (Org.). Geoprocessamento e análise ambiental. Rio de Janeiro: Bertrand Brasil, 2004.

GOOGLE CODE. Kml reference. Disponível em: <http://code.google.com/apis/kml/documentation/kmlreference.html>. Acesso em: 20/11/2008.

INFOEXAME. Downloads. Disponível em: <http://info.abril.com.br>. Acesso em: 02/09/ 2008. 
IGNARRA, L. R. Fundamentos do turismo. São Paulo: Thomson Learning, 2003

KOTLER, P. Marketing para o século XXI. 14. ed. São Paulo: Futura, 1999.

LETHAN, L. GPS fácil. Editorial paidotribo, 2001. Disponível em: <http://books.google.com.br>. Acesso em: 29/09/2008.

MIDDLETON, V. Marketing de turismo: teoria e prática. Rio de Janeiro: Campus, 2002

MINISTÉRIO DO TURISMO. Turismo de aventura - orientações básicas. Brasília: Ministério do Turismo, 2008.

- Coordenação Geral de Regionalização. Programa de Regionalização do Turismo - Roteiros do Brasil: Módulo Operacional 8: Promoção e apoio à comercialização. Brasília: Ministério do Turismo, 2007.

NEIL, J.; WEARING, S. Ecoturismo: impactos, potencialidades e possibilidades. São Paulo: Manole, 2001.

NEVES, S. Geotecnologias e turismo no pantanal mato-grossense. In: SIMPÓSIO DE GEOTECNOLOGIAS NO PANTANAL, Campo Grande, 2006. Anais eletrônicos. Disponível em: <http://www.unemat.br>. Acesso em 29/09/2008.

O'CONNOR, P. Distribuição eletrônica em turismo e hotelaria. Porto Alegre: Bookman, 2001.

PEDAL. Trilhas. Disponível em: <http://www.pedal.com.br>. Acesso em: 20/11/2008.

PORTALGPS. Fórum. Disponível em: <http://www.portalgps.com.br>. Acesso em: 02/11/2008.

PROJETOTRACKSOURCE. Downloads. Disponível em: <http://www.tracksource.org.br>. Acesso em: 20/11/2008.

SANT'ANA, A.; JARDIM, G. Turismo on-line: oportunidades e desafios em um novo cenário profissional. Observatório de Inovação do Turismo: FGV, v. 3, n. 3, 2007. Disponível em: <http://www.ebape.fgv.br/revistaoit>. Acesso em: 23/09/2008.

SANTOS, A. Metodologia científica: a construção do conhecimento. Rio de Janeiro: DP\&A, 2002.

SIGATRILHA. Trajetos. Disponível em: 〈http://www.sigatrilha.com.br>. Acesso em: 20/11/2008.

SILVEIRA, C. E.; PAIXÃO, D.; COBOS, V. Políticas públicas de turismo e a política no Brasil: singularidades e descontinuidade. Ciência \& Opinião, Curitiba, v. 3, p.121, jan./jun. 2006. 
TOPOGRAFIX. The GPS exchange format. Disponível em: <http://www.topografix.com/gpx.asp>. Acesso em: 02/09/2008.

TRAVELBYGPS. Meet our contributors. Disponível em: <http://travelbygps.com>. Acesso em: 02/09/2008.

SMITH, K.; CURRAN, K. A location-based mobile tourist guide. Tourism and Hospitality Research, Northern Ireland, v. 6, n. 2, p.180-187, 20/set./2005. Disponível em: <http://www.palgrave-journals.com>. Acesso em: 02/09/2008.

SWARBROOKE, J.; BEARD, C.; LECKIE, S.; POMFRET, G. Turismo de aventura. Conceitos e estudos de casos. Rio de Janeiro: Elsevier, 2003.

VEIGA, T.; SILVA, J. Áreas potenciais para atividades turísticas: O caso do município de Macaé. In: SILVA, J.; ZAIDAN, R. Geoprocessamento e análise ambiental. Rio de Janeiro: Bertrand Brasil, 2004.

WEBVENTURE. Onde Praticar. Disponível em: <http://webventureuol.uol.com.br>. Acesso em: 25/11/2008.

Recebido em: 19/01/2009

Aprovado em: 19/02/2009 